\title{
Ghilianella beckeri sp. nov. of Emesinae from Brazil (Hemiptera, Reduviidae)
}

\author{
Hélcio R. Gil-Santana ${ }^{1}$
}

${ }^{1}$ Laboratório de Diptera, Departamento de Entomologia, Instituto Oswaldo Cruz. Avenida Brasil 4365, Manguinhos, $21045-900$ Rio de JaneiroRJ, Brasil. helciogil@uol.com.br

\begin{abstract}
Ghilianella beckeri sp. nov. of Emesinae from Brazil (Hemiptera, Reduviidae). Ghilianella beckeri n. sp. of Emesinae from Rondônia State, Brazil is described. The most similar species to G. beckeri sp. nov. is G. approximata (McAtee \& Malloch 1925). Males of $G$. beckeri n. sp. can be separated from G. approximata because the latter has: (1) seventh tergite much shorter, slightly surpassing pygophore, and not wrinkled; (2), bifurcated medial posterior process of the pygophore; and (3) parameres without spines. Females of G. approximata can be distinguished from those of $G$. beckeri n. sp. since they have: (1) the expansions of the fifth abdominal tergum distinctly within lateral margins of disk; (2) the seventh tergite longer than wide; and (3) the eighth tergite semicircular and lightly carinate medially.
\end{abstract}

KEYWORDS. Heteroptera; Insecta; taxonomy; Rondônia.

RESUMO. Ghilianella beckeri sp. nov. de Emesinae do Brasil (Hemiptera, Reduviidae). Ghilianella beckeri sp. nov. de Emesinae proveniente do Estado de Rondônia, Brasil é descrita. A espécie mais parecida com G. beckeri sp. nov. é G. approximata (McAtee \& Malloch 1925). Machos de G. beckeri sp. nov. podem ser separados dos de G. approximata porque estes últimos possuem: (1) o sétimo tergito muito mais curto, ultrapassando levemente o pigóforo e com tegumento liso; (2) processo mediano posterior do pigóforo bifurcado; e (3) parâmeros inermes. Fêmeas de $G$. approximata podem ser distinguidas das de $G$. beckeri n. sp. por possuírem: (1) as expansões do quinto tergito abdominal distintamente dentro das margens laterais do disco; (2) o sétimo tergito mais longo do que largo; e (3) oitavo tergito semicircular, com discreta carena mediana.

PALAVRAS-CHAVE. Heteroptera; Insecta; taxonomia; Rondônia.

Amongst the entomological material collected by the late Prof. Johann Becker (1932-2004) and left to the Museu Nacional da Universidade Federal do Rio de Janeiro, specimens of a new species of Ghilianella Spinola, 1850 (Reduviidae, Emesinae) were found and is described in the present paper.

There are 58 valid species of Ghilianella with a distributional range from Guatemala to Southern Brazil (Wygodzinsky 1966; Maldonado-Capriles 1990, 1993).

The Emesinae monograph by Wygodzinsky (1966) stated a more restricted diagnosis to the members of Ghilianella, transferring many of the species included in this genus by previous reviewers of the group (McAtee \& Malloch 1925; Maldonado-Capriles1960) to Ghinallelia Wygodzinsky, 1966. The main characters given by Wygodzinsky (1966) to distinguish these two genera were: anteroventral series of appendices of fore femur with hairs or setae and asymmetrical phallus in Ghinallelia, whereas in Ghilianella the anteroventral series of appendices is composed of spiniferous processes intermixed with strong setae and the phallus is symmetrical. Wygodzinsky (1966) also pointed out that in known males of Ghilianella the parameres don't have spines and in Ghinallelia the endosoma is invariably conspicuously asymmetrical.

Ghilianella beckeri n. sp. closely resembles $G$. approximata McAtee \& Malloch, 1925.

Ghilianella approximata was originally described based on specimens collected in Bolivia (McAtee \& Malloch 1925) and deposited in the National Museum of Natural History (NMNH), Washington (Fig. 1). Posterior to the original description, Maldonado-Capriles (1960) and Wygodzinsky (1966) provided additional data about the species, including details on the male and female genitalia, extending the geographical distribution to Peru.

The type-material of Ghilianella beckeri n. sp. will be deposited in the following entomological collections: Museu Nacional da Universidade Federal do Rio de Janeiro (MNRJ), Instituto Oswaldo Cruz (IOC), Rio de Janeiro State and Johann Becker's Collection in the Museu de Zoologia da Universidade Estadual de Feira de Santana (MZUEFS), Bahia State. Terminology of morphology follows Wygodzinsky (1966); measurements (min-max) are in millimeters (mm).

\section{Ghilianella beckeri sp. nov.}

(Figs. 2-23)

Description. Male $(n=5)$. Total length: 26.0-27.0; Head: length: 1.9-2.0; ante-ocular portion: 0.8; post-ocular portion: 0.9; antennal segments: I: 12.0-13.0; II: 10.2-11.0; III: 0.8-1.0; IV: 1.6-1.7; rostral segments: I: 0.4; II: 0.5;III: 1.1. Thorax: prothorax length: 3.0-3.1; mesothorax: 5.1-5.5; metathorax: 2.83.0. Anterior legs: coxa: 3.8-4.2; femur: 5.7-6.1; tibia: 1.7-1.9; tarsus: 1.3-1.4; medium legs: femur: 13.5-16.0; tibia: 17.3-18.2; 
tarsus: $0.4-0.5$; posterior legs: femur: 18.2-20.0; tibia: 24.0-26.0; tarsus: 0.4-0.5. Abdomen: length: 12.0-12.7.

General coloration brown, last abdominal segments black. Head, thorax and abdomen with fine, short, decumbent golden to silver hairs which are denser on head, metathorax, and first four abdominal segments. Body tegument opaque. Head and thorax conspicuously granulate (Fig. 2). Legs and rostrum somewhat shiny. Head (Fig. 2,3) covered with patches of silvery hair; interantennal spine well developed, slightly curved downwards; eye round, medium-sized; dorsal interocular furrow deep; antennae long and slender, with short hairs; rostrum almost glabrous with small patch of hairs laterally on segment I and very fine and sparse ones ventrally on all segments. Thorax: mesothorax longer than prothorax and metathorax. Anterior legs: uniformly brown or in the external part of femur and base of tibia of lighter color; femur with anteroventral series of spines starting approximately posterior to third proximal large spine on posteroventral series (Fig. 4); femur with basal posteroventral spine length about 4,5x its length from base, longer than the width of the femur (Fig. 5); tibia stout, one-third the length of femur, ventrally with one series of hook-shaped denticles; tarsus not segmented, long, claws asymmetrical, the outer one much longer than inner one. Mid and hind legs long, slender, with sparse short fine hairs; femora with three flavescent dorsal macula at submedian, apical third, and apical positions. Abdomen (Figs. 6-7): basal segments straight and narrow; distal part of fourth, fifth, and basal part of sixth forming a bulbosity more pronounced ventrally; fifth tergum with very small lateral median expansions on inner side of lateral margins of disk.

Male terminalia: seventh tergite apically pointed, surpassing apex of pygophore by 1.8-2.0 $\mathrm{mm}$, tegument wrinkled (Figs. 6-7). Pygophore subrectangular (Fig. 8), semicircular in lateral view (Fig. 9); medial posterior process small, broadly round (Fig. 10). Parameres simple, symmetrical, with several setae and blunt short spine near apex (Figs. 1113). Phallus symmetrical (Fig.14-15); basal plate struts fused at base, separated only apically (Fig. 16); dorsal sclerotization of phallosoma shaped as two subparallel longitudinal bands (Fig. 16). Endosoma wall (Figs. 17-19) with several spicules and two pairs of endosomal processes; the basal ones longer, asymmetrical, left one more developed and longer than the right one, serrated at all faces; the distal processes rounded, smaller and with spicules on outer margin.

Female. Total length $(n=2): 25.0-25.5$; Head: length: 2.0-2.1; ante-ocular portion: 0.9 ; post-ocular portion: $0.8-0.9$; antennal segments: I: 11.5-12.0; II: 8.8; III: 0.8; IV: 1.5-1.7; rostral segments: I: 0.4; II: 0.5;III: 1.2-1.3. Thorax: prothorax length: 3.1-3.3; mesothorax: 5.0-5.1; metathorax: 2.7-3.0. Anterior legs: coxa: 4.2; femur: 6.3; tibia: 1.9 ; tarsus: 1.3-1.4; medium legs: femur: 15.2-17.8; tibia: 15.4-17.5; tarsus: 0.5 ; posterior legs: femur: 18.0-19.0; tibia: 23.1-23.3; tarsus: 0.5. Abdomen: length: 11.8-12.0.

Similar to male. Abdomen: Fifth segment bulbosity less developed than in males (Figs. 20-21); fourth and sixth segments more dilated in their apical and basal parts respectively (Fig. 20); lateral median expansions reaching or lightly exceeding margin of disk (Fig. 20); ventral median margin of seventh sternite pointed (Fig. 21-22). Genital segments: Eighth and ninth tergites forming a continuous surface, almost vertical (Figs. 21-22); eighth tergite subtriangular without carina; ninth tergite with three pairs of transverse wrinkles laterally and dilated apex (Fig. 23).

Etymology. The species epithet is named in honor of the late Prof. Johann Becker (Museu Nacional da Universidade Federal do Rio de Janeiro), collector of the species and also for his important contributions to Brazilian Entomology.

Discussion. The new species is described in Ghilianella mainly because its anteroventral series of the fore femur bears conspicuous spiniferous processes intermixed with strong setae. Other characters of importance to the generic placement appear to disagree in the new species and are discussed below. Wygodzinsky (1966) observed that parameres of species of Ghilianella don't have spines, such as those found in several species of Ghinallelia. Therefore, the presence of a blunt apical spine in the parameres of Ghilianella beckeri n. sp. (Figs. 11-13) differentiates this species from others included in Ghilianella.

Furthermore, Wygodzinsky (1966) reinforced the fact that the phallus is symmetrical in Ghilianella species and the endosoma is conspicuously asymmetrical in Ghinallelia species; G. beckeri n. sp., however, has a slightly asymmetry in the basal processes of the endosoma, the left one being more developed and longer than the other. Further studies may show if these two characteristics observed in G. beckeri n. sp. - blunt spine in parameres and a slight asymmetry in basal processes of endosoma - are peculiar to the new species or are shared with other species in the genus Ghilianella and must be recognized in an extended diagnosis of the genus.

Among the 58 species of Ghilianella, several species seems to share some similarities and groups can be recognized. Considering the descriptions and keys provided by McAtee \& Malloch (1925), Maldonado-Capriles (1960), and Wygodzinsky (1966) and also the phallosoma aspect as depicted in Wygodzinsky's drawings (1966), the species most closely resembling to $G$. beckeri n. sp. is G. approximata. These two species share the following set of characters that distinguish them from others species of Ghilianella: (1) apterous condition; (2) Head and thorax conspicuously granulate; (3) interantennal spine well developed; (4) mesothorax longer than prothorax; (5) fore femur not constricted at level of base of series or spines; (6) fore tarsus with two claws; (7) abdomen with bulbous swelling beyond middle and lateral expansions on fifth tergite; (8) fifth tergite the widest one; males with: (9) lateral median expansions of fifth tergum of male on inner side of lateral margins of disk; (10) sixth tergite not wholly incorporated into bulbosity, which is distinctly subterminal; (11) seventh tergite long; and, (12) process of pygophore small.

Ghilianella approximata was originally described based on specimens collected in Bolivia (McAtee \& Malloch 1925) and deposited in the National Museum of Natural History 

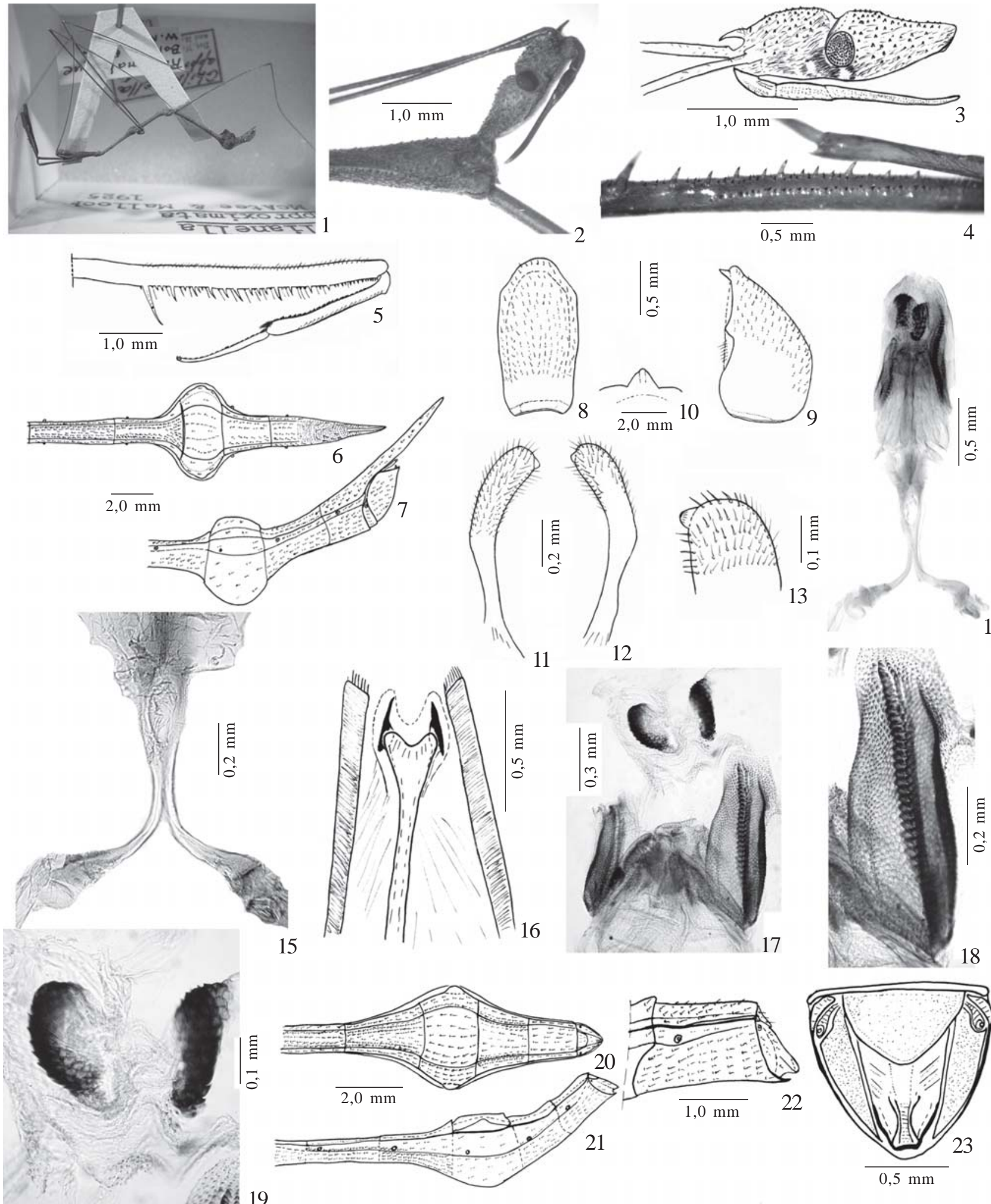

Figs. 1-23. 1. Ghilianella approximata McAtee \& Malloch, 1925, holotype male, lateral view, courtesy of Dimitri Forero; 2-23. Ghilianella beckeri n. sp., 2, holotype male, head and anterior part of thorax, lateral view; 3, paratype male, head, lateral view; 4, anterior leg, medium portion, ventral view; 5, anterior leg, lateral view; 6, apex of abdomen of male, dorsal view; 7, apex of abdomen of male, lateral view; 8 , pygophore, ventral view; 9, pygophore, lateral view; 10, process of pygophore, posterior view; 11, left paramere, ventral view; 12, left paramere, dorsal view; 13, apex of left paramere, dorsal view; 14, phallus, dorsal view; 15, articulatory apparatus, dorsal view; 16, phallosoma contents: apex of struts and dorsal sclerotization of phallobase, dorsal view; 17, Endosoma, dorsal view; 18, Endosoma, lateral part of basal process; 19, Endosoma, distal processes; 20, apex of abdomen of female, dorsal view; 21, apex of abdomen of female, lateral view; 22, genital segments of female, lateral view; 23, genital segments of female, posterior view. 
(NMNH), Washington. Posterior to the original description, Maldonado-Capriles(1960) and Wygodzinsky (1966) provided additional data about the species, including details on the male and female genitalia, extending the geographical distribution to Peru.

Males of $G$. beckeri sp. nov. can be separated from $G$. approximata because the latter has: (1) seventh tergite much shorter, slightly surpassing pygophore, and not wrinkled; (2), bifurcated medial posterior process of the pygophore ; and (3) parameres without spines. Females of G. approximata can be distinguished from those of $G$. beckeri $\mathrm{n}$. sp. since they have: (1) the expansions of the fifth abdominal tergum distinctly within lateral margins of disk; (2) the seventh tergite longer than wide; and (3) the eighth tergite semicircular and lightly carinate medially.

Material examined. BRAZIL, Rondônia State, Ouro Preto d'Oeste ( $\left.10^{\circ} 52^{\prime} \mathrm{S} ; 61^{\circ} 58^{\prime} \mathrm{W}\right)$, 06. XI.1983, Johann Becker leg., holotype male, two males and one female paratypes (MNRJ); one male and one female paratypes (MZUEFS); one male paratype (IOC).
Acknowledgments. Dimitri Forero (Cornell University) for suggestions, information and photos of the type of G. approximata.

\section{REFERENCES}

Maldonado-Capriles, J. 1960. Assassin bugs of the genus Ghilianella in the Americas (Hemiptera, Reduviidae, Emesinae) Proceedings of the United States National Museum 112: 393-450.

Maldonado-Capriles, J. 1990. Systematic Catalogue of the Reduviidae of the World (Insecta: Heteroptera). Caribbean Journal of Sciencies, special edition, Mayagüez, 694 p.

Maldonado- Capriles, J. 1993. A new species of Ghilianella and the female of Ghinallelia claviventris (Bergroth) (Heteroptera: Reduviidae: Emesinae) Proceedings of the Entomological Society of Washington 95: 558-561.

McAtee, W. L. \& J. R. Malloch. 1925. Revision of the American bugs of the Reduviid subfamily Ploiariinae. Proceedings of the United States National Museum 67: 1-135.

Wygodzinsky, P. 1966. A monograph of the Emesinae (Reduviidae, Hemiptera). Bulletin of the American Museum of Natural History 133: 1-614. 